\title{
MELHORANDO O PROCESSO DE AQUISIÇÃO DE MATERIAIS E COMPONENTES PARA PROTÓTIPOS DE NOVOS PRODUTOS
}

\section{IMPROVING THE PROCESS OF ACQUISITION OF MATERIALS AND COMPONENTS FOR PROTOTIPES OF NEW PRODUCTS}

\author{
Sanderson Barbalho ${ }^{1}$; Eduardo Henrique Richter ${ }^{2}$; Henrique Rozenfeld ${ }^{3}$ \\ ${ }^{1}$ OPTO ELETRÔNICA S.A. - São Carlos - Brasil sanderson@opto.com.br \\ ${ }^{2}$ Universidade de São Paulo - USP - São Carlos - Brasil edhenrichter@gmail.com \\ ${ }^{3}$ Universidade de São Paulo - USP - São Carlos - Brasil roz@sc.usp.br
}

Resumo

$O$ artigo discute o quão crítica é a aquisição de materiais e componentes para a fabricação de protótipos de novos produtos. São apresentadas as principais análises de literatura cientifica sobre o tema, assim como estudos que discutem quais aspectos tornam crítica a atividade de aquisição de itens. É apresentada a teoria relacionada ao desenvolvimento de produtos enxutos. Apresenta-se a empresa na qual foram realizadas atividades de melhoria no processo de aquisição de itens, especialmente importados. Demontra-se que através do acompanhamento sistemático das importações foi possível reduzir significativamente o lead-time dos itens importados. Apresenta-se uma proposta de melhoria do processo utilizando conceitos de desenvolvimento enxuto para racionalizar seu fluxo de informações e reduzir os tempos de fila e o lead-time total das aquisições de itens importados.

Palavras-chave: Desenvolvimento de produtos, Importações, Desenvolvimento Enxuto.

\section{Introdução}

O processo de desenvolvimento de produtos (PDP) é amplamente reconhecido como sendo eminentemente um processo que transforma informações (CLARK e FUJIMOTO, 1991; McMANUS, 2003). Tratando-o desta forma é fácil entender sua diferenciação quanto aos processos característicos da manufatura e montagem. Entretanto, o PDP é também reconhecido como um processo cujo cerne está no ciclo projetar-fabricar-testar (WHEELWRIGHT e CLARK, 1992; CREVELING et al. 2003), o que traz à tona os materiais, componentes e partes necessárias à fabricação de protótipos.

Essas duas realidades se encontram neste artigo. Ele está num contexto em que uma média empresa brasileira desenvolve produtos de tecnologia de ponta. Nesse contexto há um fluxo de informações intenso entre projetistas, compradores, pessoas de manufatura, de marketing etc. Essas pessoas atuam com o objetivo comum de desenvolver protótipos funcionais que permitam aos 
clientes avaliarem o produto como um todo e suas soluções em particular.

Como a empresa pesquisada viveu uma situação de atraso na entrega de protótipos estabelecidos em contrato em função de atrasos no fornecimento de itens comprados, optou-se por estabelecer ações de melhoria relacionadas apenas à aquisição de materiais e componentes necessários aos protótipos. Assim, o artigo analisa os tempos e custos do processo de aquisição de novos itens, demonstra que houve melhoria nos indicadores de tempo em função de estar sendo realizado um acompanhamento mais sistemático das aquisições e apresenta uma proposta de melhoria de processo com base nas teorias de desenvolvimento enxuto.

A metodologia utilizada no trabalho foi a pesquisa-ação conforme descrita em THIOLENT (1997). Foram utilizadas técnicas de observação participante e direta, assim como de entrevistas não-estruturadas, para o levantamento dos dados necessários à estruturação do acompanhamento das aquisições e da proposta de melhoria deste processo.

\section{Aquisição e importação em processos de desenvolvimento de novos produtos}

Na literatura do desenvolvimento de produto as aquisições são analisadas mais comumente sob a ótica das estratégias de co-desenvolvimento que as companhias constroem para projetar conjuntamente um produto. Este tipo da discussão foi apresentada por CLARK e FUJIMOTO (1991), que descrevem quatro tipos genéricos de partes de terceiros em projetos de novos produtos: partes proprietárias, partes tipo caixa-preta, partes funcionais com detalhes controlados, e partes estruturais com detalhes controlados.

Comumente a aquisição de itens no desenvolvimento de produtos é relacionada com a geração de protótipos. WHEELWRIGHT e CLARK (1992) argumentam que os especialistas em prototipagem de uma determinada empresa tendem a focar mais em ganhos de escala e redução de custos com os protótipos do que em retorno rápido para os projetistas. Ao subcontratar, a gerência de projeto pode decidir o quanto a companhia está disposta a pagar por ciclos rápidos. ULRICH e EPPINGER (1995) enfatizam que a aquisição de itens "caixa preta" é interessante quando a empresa deseja aliviar sua equipe de engenharia de responsabilidades com protótipos de partes, e fazêe-la se dedicar à integração e teste do novo produto como um todo.

CHRISSIS et al. (2006) localiza o processo de aquisição dentro do modelo de integração de maturidade e capabilidade (CMMI) em duas áreas de processo denominadas "gerência de fornecedores integrada" e "gerência contratos de fornecimento". A primeira é baseada na já mencionada filosofia de co-desenvolvimento e a segunda trata da aquisição de itens de estoque e de itens de produção por pedido. A proposta do CMMI é baseada no estabelecimento de um acordo formal com o fornecedor. 
Alguns estudos tratam da gerência de processos de aquisição em países em desenvolvimento. MANAVAZHI e ADHIKARI (2002) estudam os atrasos no processo de aquisição de projetos de rodovias no Nepal. Os autores identificam uma possível correlação entre o impacto de custo de um item e seu atraso quanto a data de entrega programada. Para eles há problemas estruturais da cadeia de fornecimento, tais como monopólios e dificuldades de importação, que são responsáveis por $79 \%$ dos atrasos nas aquisições. Em Ghana, FRIPONG, OLUWOYE e CRAWFORD (2003) entrevistaram proprietários, consultores e contratantes de projetos de perfuração de poços e alegam que os principais fatores que afetam o atraso em projetos e a elevação do custo final estão relacionados às aquisições: ausência de gerência eficaz de aquisições, entrega atrasada dos itens e dificuldades de importação. Outras causas são falhas na gestão de contratos e dificuldades de numerário para itens com pagamento antecipado.

\section{A abordagem enxuta no desenvolvimento de produtos}

A abordagem enxuta surgiu quando pesquisadores do Massachussets Institute of Technology desenvolveram uma pesquisa mundial sobre os desafios da indústria automobilística no final dos anos 80. Seus achados deram origem ao conceito de produção enxuta (WOMACK e JONES, 1992) amplamente utilizado no chão de fábrica em diversos setores industriais ao redor do mundo.

Ao final dos anos 90, as pesquisas em produção enxuta passaram a abordar o processo de desenvolvimento de produtos como uma área potencial de melhoria utilizando os conceitos previamente desenvolvidos para o chão de fábrica. Por exemplo, a proposta de McMANUS (2003) para a aplicação do abordagem enxuta no PDP é baseada em:

\footnotetext{
"... mapear este processo 'de porta a porta', entendendo seus limites, os vários atores com os quais interage e aquilo que para eles configura valor, seu fluxo de informação, filas, e atividades... encontrar os desperdícios, ineficiências, e ações que não agregam valor e podem ser eliminadas rapidamente para atingir um 'estado futuro', e gerar idéias para um possível 'estado ideal' que sirva como meta." (idem ibidem, p. 5)
}

Portanto, a abordagem de McMANUS é baseada no mapeamento do processo de agregação de valor a informações que vão sendo desenvolvidas ao longo do PDP. O mapeamento do processo de desenvolvimento iniciaria com um 'mapa de limites' que identificaria as entradas e saídas do processo. A definição clara da saída do processo, assim como de seu valor para os clientes (consumidor final, acionistas, etc.), é fundamental para que o processo seja detalhado em tarefas.

Uma vez identificadas as tarefas necessárias ao projeto, elas devem ser classificadas em algum dos três tipos possíveis definidos pelo autor:

- Tarefas que agregam valor direto: tais como, as de definição do produto final com desempenho funcional desejado, as de definição do processo de produção e entrega etc. 
- Tarefas necessárias que não agregam valor: as que precisam ser realizadas se a empresa não provê um sistema de gestão que as torne comuns no seu cotidiano, como por exemplo, facilitar a comunicação, investir na satisfação das pessoas com o trabalho etc.

- Tarefas intermediárias: em algumas situações agregam valor e em outras não, tais como documentação do produto, atividades habilitadoras como aquisição de componentes etc.

A partir de então, o autor sugere que as tarefas consideradas necessárias ao desenvolvimento do novo produto sejam utilizadas para elaborar mapas com o "fluxo básico de informações entre elas". Na elaboração dos mapas devem ser ilustradas algumas métricas básicas para que se tomem decisões relacionadas com a melhoria do fluxo, tais como:

- Tempo de ciclo (CT): tempo necessário para realizar uma tarefa;

- Tempo em fila (QT): tempo que um trabalho espera até o processo seguinte o utilize;

- Tempo de processo principal (CPT): horas de trabalho contínuo gasto no cerne da tarefa (excluindo set-up, ajustes, levantamento de informações etc. As vezes é chamado de tempo de valor agregado (VAT);

- Eficiência: IPT/CT, CPT/CT ou CPT/IPT; e

- Lead time: tempo do reconhecimento da necessidade pela tarefa até a compleição da tarefa.

Mapas de estado atual são analisados quanto à existência de tarefas que não se encaixam em nenhuma das três tipologias discutidas anteriormente, e que portanto, podem ser denominadas como não-agregadoras de valor. O fluxo é então analisado quanto a possíveis "desperdícios de informação": (1) atraso da disponibilização da informação; (2) estoques de informações grandes, complexos ou obsoletos; (3) informações excessivamente trabalhadas; (4) criação e disponibilização de informações desnecessárias; (5) problemas no transporte de informações; (6) movimentos desnecessários como reformatação ou dificuldades de acesso direto; e (7) informações incompletas, sem revisões, verificações etc.

Outras abordagens de desenvolvimento enxuto vêm ganhando espaço na bibliografia especializada, como por exemplo, MASCITELLI (2004) que aporta sua teoria na redução de custos como chave para o aumento da lucratividade de uma empresa e na identificação de direcionadores de custo que são afetados diretamente pelo PDP.

Enfim, TAPPING e SHUKER (2003) discutem a aplicação dos conceitos de produção enxuta para processos organizacionais que tenham caráter administrativo. Embora não enfoquem especificamente o PDP, o ferramental desenvolvido pelos autores é capaz de ser utilizado em diversas situações envolvidas no desenvolvimento de produtos. Segundo os autores, a exemplo da manufatura, os processos administrativos ocorrem em seqüências predeterminadas, podem ser medidos em relação a tempo e quantidades e contém, no mais das vezes, alguns procedimentos 
redundantes ou que poderiam ser executados em uma outra ordem de eventos que melhore seus resultados finais. Para os autores, apenas de 5\% a 30\% do tempo despendido em um processo administrativo equivale ao valor que ele agrega à organização. O restante está disperso entre os sete desperdícios já mencionados.

No presente trabalho, o ferramental proposto por TAPPING e SHUKER (2003) foi utilizado para propor melhorias no processo de aquisição de materiais e componentes importados a serem utilizados em projetos de novos produtos.

\section{A empresa pesquisada e o volume de aquisições de itens para novos produtos}

A empresa na qual foi realizado o trabalho aqui descrito foi fundada em 1985 e conta, atualmente com cerca de 350 funcionários divididos na sede em São Carlos, um escritório comercial em São Paulo, um escritório em Porto Alegre/RS, um em Fortaleza/CE e outro em Miami, Estados Unidos. Há representantes na Europa, na Ásia e na Oceania. As unidades de São Carlos, Porto Alegre e Fortaleza realizam operações industriais, as demais, apenas vendas e assistência técnica. Apenas em São Carlos há desenvolvimento de produtos.

O enfoque da empresa está no desenvolvimento de tecnologias e equipamentos de ponta. Ela tem em seu portifólio de produtos alguns equipamentos industriais, tais como o medidor a laser para controle de pneus e multiposicionador laser; produtos da área médica como microscópios cirúrgicos oftálmico e odontológico, retinógrafos e fotocoaguladores para cirurgia de retina; produtos de defesa; e câmeras de satélites de monitoramento ambiental que capturam e processam imagens da Terra.

A Figura 1 apresenta o organograma da empresa. A empresa compõe-se de cinco departamentos, dois deles podendo ser consideradas divisões de projeto (filmes finos e pesquisa e desenvolvimento), um departamento comercial, um de manufatura e outro de administração geral. Os novos produtos desenvolvidos pela companhia ocorrem nos departamentos de pesquisa e desenvolvimento e de filmes finos. As compras de materiais e componentes são realizadas pelos departamentos de operações industriais - caso das compras nacionais - e de administração compras no mercado externo.

Figura 1 - Organograma da empresa pesquisada

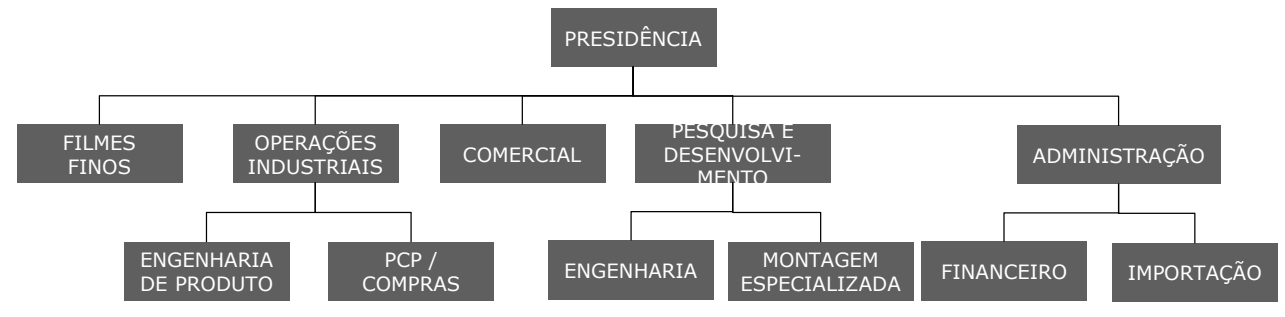


A Figura 2 descreve a quantidade de itens adquiridos por mês para os projetos em desenvolvimento, conforme sejam importados ou nacionais. A figura revela que a grande maioria dos itens nacionais consta com seu processo de aquisição concluído e existem processos de importação que se arrastam desde agosto de 2006. Examinando as compras somente iniciadas após setembro 2006 , pode-se ver que quase $40 \%$ são de itens importados.

Figura 2 - Quantidade de itens em Aquisição Importado versus Nacional. (Fonte: primária, 15/04/07)

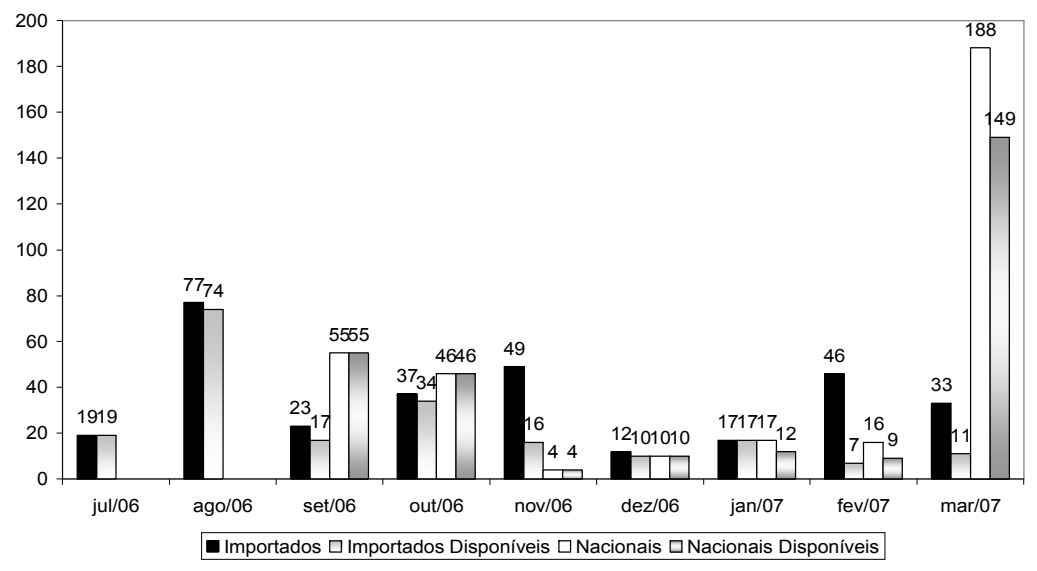

A

Figura 3 mostra quanto do valor despendido pela companhia para comprar um item é, de fato, o seu preço. Os preços dos itens importados chegaram a representar apenas $25 \%$ do custo total da importação. Por sua vez, os preços dos nacionais se mantêm em 98\% do custo total.

Figura 3 - Média de preços dos itens sobre o custo total de compra. (Fonte: primária, 15/04/07)

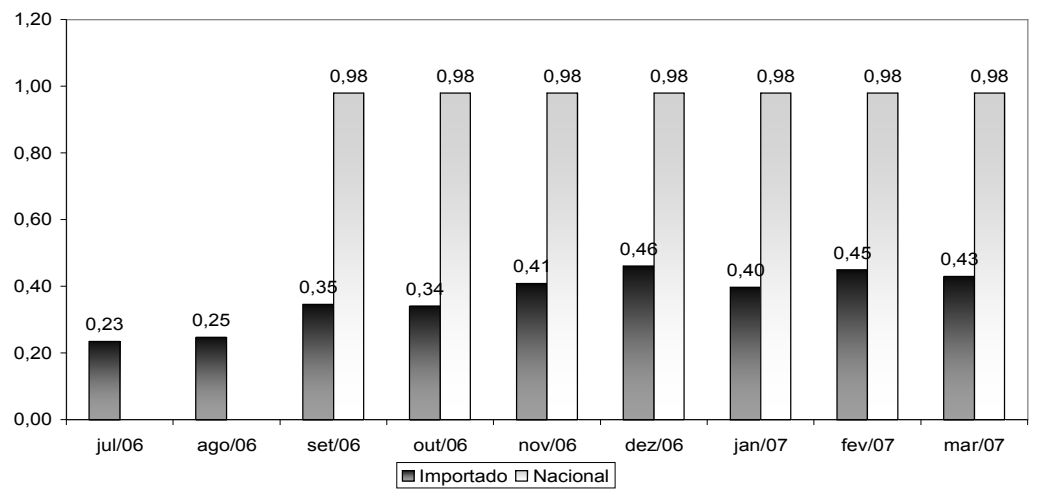

\section{Conhecendo e melhorando o processo de aquisição de itens para os novos produtos}

A grande quantidade de itens importados (Figura 2) e o forte impacto do processo de importação em si no custo do item disponibilizado para uso ( 
Figura 3) justificaram o interesse da companhia na proposição de melhorias no processo de importação de materiais e componentes para os projetos de novos produtos. O processo de importação foi inicialmente mapeado através da identificação de seus principais marcos, ilustrados na Figura 4.

Figura 4 - Marcos das etapas do processo de importação
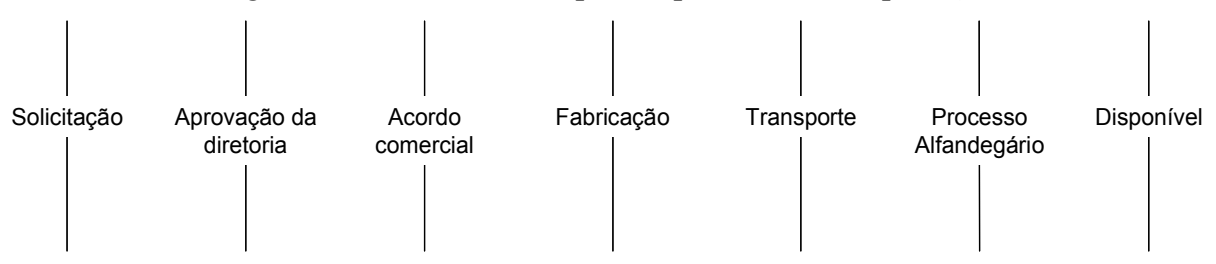

Inicialmente é realizada uma solicitação de compra que é submetida à diretoria da empresa através de um pedido com prazos e valores de compra. Quando aprovada para compra definitiva, é realizado acerto comercial com forma de pagamento, negociação de frete etc. O item é fabricado e transportado comumente via aérea (pequenos volumes) ou naval (grandes volumes). Ao chegar ao Brasil o item passa por análise da alfândega e quando liberado é transportado até a empresa e disponibilizado para uso.

Esse processo passou a ser monitorado com a situação dos itens em aquisição sendo atualizada semanalmente pela área de projetos junto ao setor de importação da empresa. A Figura 5 ilustra o tempo médio entre os marcos consecutivos ilustrados na Figura 4. Como pode ser visto, o maior lead-time parcial é o tempo para concluir o 'acordo comercial', representado pela finalização da aprovação da diretoria até o momento em que a fabricação do item (ou seu transporte) é iniciada. Este suposto contra-senso pode ser explicado pelo fato de que quase todos os itens importados são de pronta entrega (tempos de fabricação nulos). Adicionalmente, os dados indicam que o tempo transcorrido entre a chegada de um item ao Brasil e sua liberação alfandegária é mais longa do que o próprio transporte intercontinental.

Figura 5 - Tempo médio entre cada marco do processo de aquisição em horas. (Fonte: primária, 15/04/07)

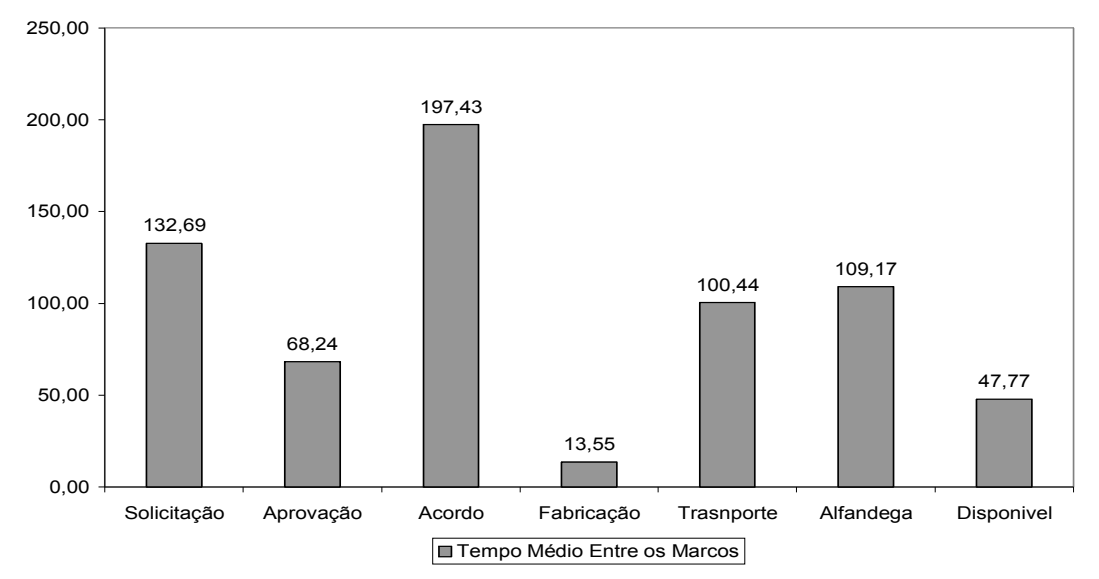


A Figura 6 apresenta o lead-time dos itens importados e nacionais por mês. Observa-se que houve uma melhoria significativa do lead-time dos itens importados quando comparada com a redução do lead-time dos nacionais. Em setembro de 2006 a relação entre a média dos lead-times dos importados sobre a dos nacionais era de 169,60/28,78 (1 para 5,9) enquanto em março de 2007 está em 53,17/23,24 (1 para 2,2).

Os dados da Figura 6 demonstram que o mero acompanhamento do processo de importação permitiu reduzir o lead-time dos itens importados. Permitiu também determinar os tempos de processo e de fila das importações, aspecto discutido a seguir.

Figura 6 - Lead Time mensal e médias em dias (Fonte: primária, 15/04/07)

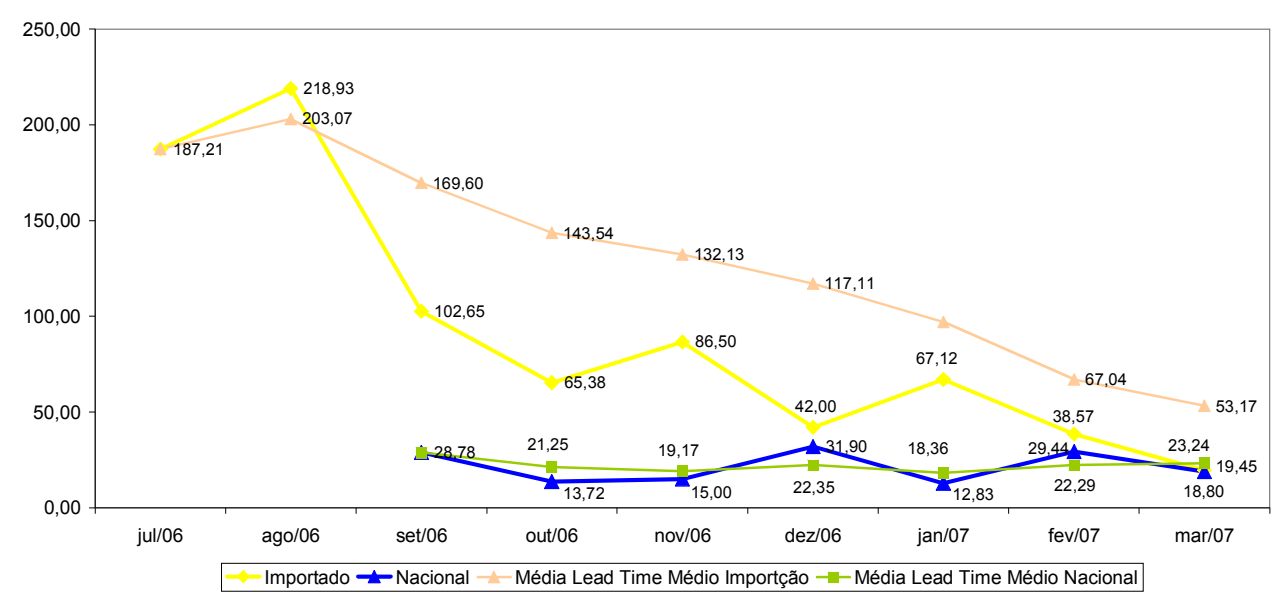

\section{Aplicação de conceitos de desenvolvimento enxuto na melhoria do processo de aquisição de itens importados}

Considerando que o lead-time médio da aquisição dos itens importados é a soma de seus lead-times parciais apresentados na Figura 5, pode-se verificar que as atividades eminentemente realizadas dentro da empresa - atividades de processos puramente administrativos - representavam cerca de $60 \%$ do tempo gasto com a aquisição de um item importado. Esse número motivou a utilização do ferramental discutido no item 3 para estudar mais a fundo o processo de importação e propor melhorias a ele.

A Figura 7 apresenta o mapa do estado atual do processo de aquisição de itens importados na empresa, conforme os construtos propostos por TAPPING e SHUKER (2003). 
Figura 7 - Mapa do estado atual do processo de importação

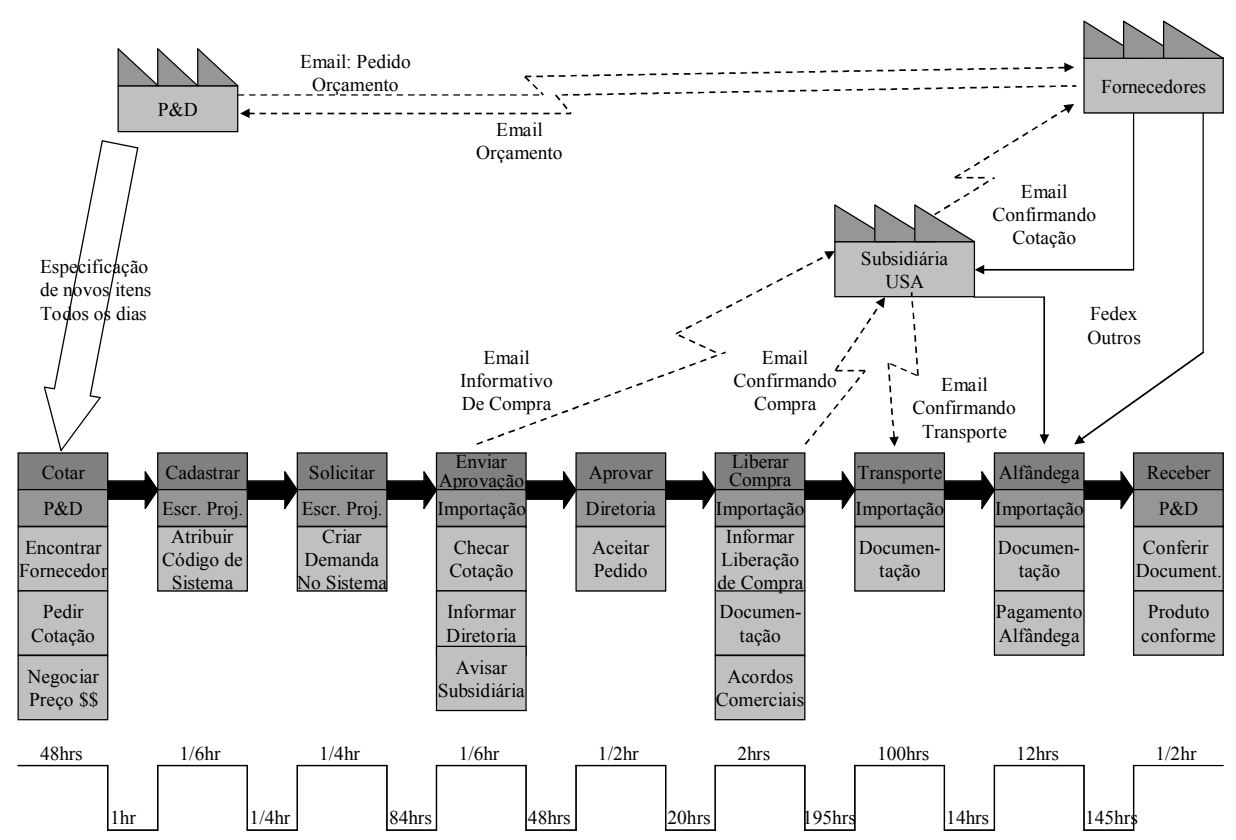

Os projetistas do departamento de P\&D geram a necessidade de compra de um novo item. Caso o item em questão esteja sendo comprado pela primeira fez, o responsável técnico procura por um fornecedor adequado e pede uma primeira cotação. Todos os dias são passadas solicitações de importação a uma média de 20 itens por dia. O escritório de projetos do P\&D é responsável por cadastrar e colocar a solicitação destes itens no sistema de informações gerenciais da empresa. Tal solicitação então é remetida para o setor de importação que verifica se todas as informações necessárias constam na cotação, coloca o pedido de compra para ser aprovado pela diretoria e emite um aviso de compra para a subsidiária norte-americana. Aceito, o pedido de compras é devolvido para o setor de importação que notifica a subsidiária norte-americana e autoriza a compra. A subsidiaria americana confirma a cotação com o fornecedor e executa a compra. É comum nos processos de importação que haja o pagamento imediato dos itens, porém eventualmente são fechados acordos comerciais.

O item entra em seu processo de fabricação e transporte. Nessa etapa, o setor de importação deve preparar a documentação para o envio e a entrada do item no Brasil. O transporte pode se dar por duas formas: o item ser enviado direto para o Brasil ou passar pela subsidiária norte-americana antes de ser enviado. Quando o item aporta no Brasil, é encaminhado à alfândega que faz a conferência, autoriza sua entrada e o tarifa de acordo com a legislação vigente. Após o pagamento destas taxas (desembaraço), o item é liberado para transporte até as dependências da empresa onde são realizados procedimentos de liberação de nota fiscal para finalmente ser encaminhado ao setor técnico que o requisitou.

Considerando todo o processo descrito na Figura 7, têm-se aproximadamente 670,83 horas de processo das quais 163,58 horas $(24,4 \%)$ são tempos de ciclo (CT) e 507,25 horas $(75,6 \%)$ são 
tempos de fila (QT).

O mapa de estado futuro apresentado na Figura 8 foi construído para melhorar o processo reduzindo os tempos de fila e racionalizando o fluxo de informações. A proposta difere do processo atual em dois aspectos. Primeiramente, seria alocado ao setor de importação um supermercado de recursos financeiros, um orçamento mensal a ser controlado pelos diretores através de relatórios semanais. Isso resolveria o problema de numerário para as importações que exigem pagamento antecipado. Adicionalmente, seria estabelecido um critério de importação no qual um limite de custo é estabelecido para que o setor de importação realize as aprovações. Nesse caso, mesmo que seu orçamento mensal permita, caso a compra exceda o critério, a diretoria teria de aprovar a transação.

Figura 8 - Mapa do estado futuro do processo de importação

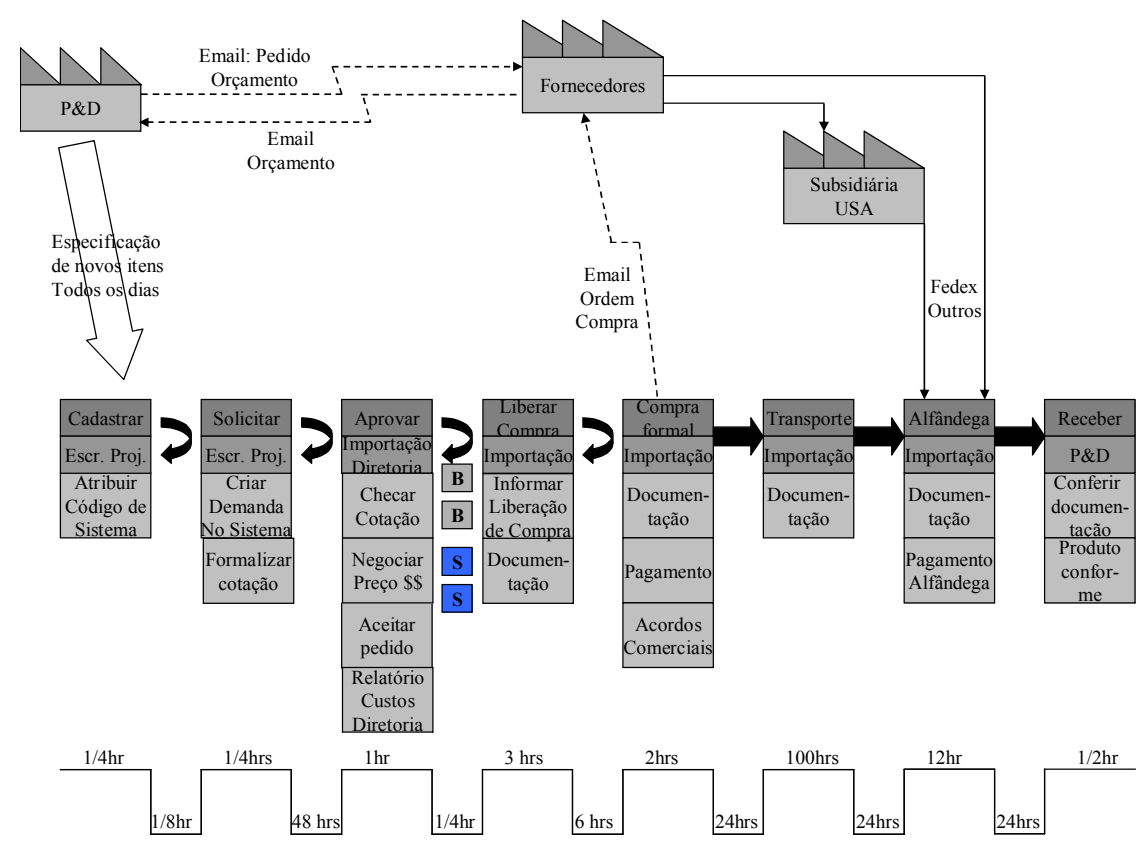

A segunda diferença básica estaria no papel desempenhado pela subsidiaria americana. Ao invés de estabelecer fluxo de informação direto com o fornecedor, a subsidiária funcionaria apenas como broker para serviços logísticos no caso de itens de pequeno porte. Dessa forma, racionaliza-se o fluxo de informações entre a empresa considerada e seu fornecedor externo. Adicionalmente, foi incorporado um processo denominado "compra formal". Esse processo, antes realizado pela subsidiária americana passa a ser realizado pelo setor de importação.

A proposta ilustrada na Figura 8 permite uma redução de 57,6\% no lead-time médio das importações. Além disso, permite 76,9\% de redução do tempo de fila no processo.

\section{Conclusão}

O artigo apresenta uma aplicação de conceitos de melhoria de processos no PDP de uma 
empresa de alta tecnologia. A melhoria abordou o processo de aquisição de itens importados. Inicialmente, o processo passou a ser monitorado. No estágio atual, uma proposta de mudança foi elaborada e está em discussão na companhia.

Os próximos passos do trabalho são a apresentação do material aos envolvidos no processo de aquisição e o detalhamento da proposta, especificando valores para o supermercado a ser alocado ao setor de importação e os critérios pelos quais esse setor se guiará na aprovação de determinados itens importados. Uma vez estabelecida a estrutura organizacional do processo de aquisição, serão propostos valores para o takt time do processo, o que permitirá construir as metas para os setores envolvidos.

\begin{abstract}
This paper discusses how critical is the procurement of materials and components for the manufacture of prototypes of new products. The analysis of major scientific literature on the subject is presented, as well as studies that discuss aspects which make the activity of purchasing items critical. The theory related to lean product development is presented. The company in which the activities were undertaken to improve the process of purchasing items is presented. The actions improvements were specially applied to the purchase process of imported items. The results demonstrate that the monitoring of imports has significantly reduced procurement lead-times. Some concepts of lean development are used to build the process improvement proposal. It aims to rationalize the process information flow, and to reduce queues and imports lead time.
\end{abstract}

Key-words: Product Development, Imports, Lean Development.

\title{
Referências
}

CHRISSIS, M. B. et. al. CMMI: Guidelines or process integration and product improvement. Boston, Massachussets, United States, 2006.

CLARK, K. B.; FUJIMOTO, T. Product development performance: strategy, organization and management in the world auto industry. Harvard Business School Press, Boston, Massachussets, United States, 1991.

CREVELING, C.M. et al. Design for six-sigma in technology and product development. New Jersey, United States, Prentice Hall, 2003.

EUROPEAN COMMISSION FOR SPACE STANDARDIZATION. ECSS-M-10B. Space project management project breakdown structures. Noordwijk, The Netherlands, 2003.

FRIPONG, Y.; OLUWOYE, J.; CRAWFORD, L. Causes of delay and cost overruns in construction of groundwater projects in developing countries; Ghana as a case study. Intenational Journal of Project Management, 21, 321-326, 2003.

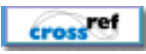

MANAVAZHI, M.R.; ADHIKARI, D. K. Material and equipment procurement delays in highway projects in Nepal. Intenational Journal of Project Management, 20, 627-632, 2002.

cross ${ }^{\text {ref }}$

MASCITELLI, R. The lean design guidebook: everything your product development team needs to slash manufacturing costs. Technology perspectives, Northridge, CA, 2004. 
McMANUS, H. Product development value stream analysis and mapping manual (PDVSM) - Alpha draft. Lean Aerospace Initiative, Center for Technology, Policy, and Industrial Development. Cambridge, Massachusetts, Massachusetts Institute of Technology, 2003.

TAPPING, D; SHUKER, T. Value Stream Management for the Lean Office. Productivity Press, New Your, New York, United States, 2003

THIOLLENT, M. Pesquisa-ação nas organizações. São Paulo/SP: Editora Atlas, 1997.

ULRICH, K.T.; EPPINGER, S.D. Product design and development. McGraw-Hill Inc. United States, 1995.

WHEELWRIGHT, S. C.; CLARK, K. B. Revolutionizing product development process: quantum leaps in speed, efficiency, and quality. New York, United States, The Free Press, 1992.

WOMACK, J; JONES, D. A máquina que mudou o mundo. Trad. Ivo Korytowski. Rio de Janeiro: Campus, 1992.

\section{Autores:}

Nome completo: Sanderson César Macêdo Barbalho

Filiação institucional: OPTO ELETRÔNICA S.A.

Departamento: Pesquisa e Desenvolvimento

Função ou cargo ocupado: Engenheiro de Desenvolvimento Sênior

Endereço completo para correspondência: Rua Abraão João, 1081, Jardim Bandeirantes, São

Carlos, São Paulo, Brasil, 13562-150

Telefones para contato: 1635015099 / 1692015795

e-mail:scmbbr@yahoo.com.br

Nome completo: Eduardo Henrique Richter

Filiação institucional: OPTO ELETRÔNICA S.A.

Departamento: Pesquisa e Desenvolvimento

Função ou cargo ocupado: Engenheiro de Desenvolvimento Júnior

Endereço: Rua Joaquim A. R. de Souza, 1071, Jardim Santa Felícia, São Carlos, São Paulo, Brasil, 13563-330

Telefones para contato: 1621067065 / 1699626039

e-mail:edhenrichter@gmail.com

Nome completo: Henrique Rozenfeld

Filiação institucional: UNIVERSIDADE DE SÃO PAULO

Departamento: Engenharia de produção

Função ou cargo ocupado: Professor Titular

Endereço: Av. Trabalhador São-Carlenses, 400, São Carlos, São Paulo, Brasil, 13550-500 
Telefones para contato: 1621067065 / 1699626039

e-mail:roz@sc.usp.br 